\title{
Wave Propagation in Rocks - Investigating the Effect of Rheology
}

\author{
Tamás Fülöp ${ }^{1 *}$ \\ ${ }^{1}$ Department of Energy Engineering, Faculty of Mechanical Engineering, Budapest University of Technology and Economics, Bertalan \\ Lajos 4-6, 1521 Budapest, Hungary \\ *Corresponding author, e-mail: fulop@energia.bme.hu
}

Received: 02 April 2020, Accepted: 18 August 2020, Published online: 28 September 2020

\begin{abstract}
Rocks exhibit beyond-Hookean, delayed and damped elastic, behaviour (creep, relaxation etc.). In many cases, the PoyntingThomson-Zener (PTZ) rheological model proves to describe these phenomena successfully. A forecast of the PTZ model is that the dynamic elasticity coefficients are larger than the static (slow-limit) counterparts. This prediction has recently been confirmed on a large variety of rock types. Correspondingly, according to the model, the speed of wave propagation depends on frequency, the high-frequency limit being larger than the low-frequency limit. This frequency dependence can have a considerable influence on the evaluation of various wave-based measurement methods of rock mechanics. As experience shows, commercial finite element softwares are not able to properly describe wave propagation, even for the Hooke model and simple specimen geometries, the seminal numerical artefacts being instability, dissipation error and dispersion error, respectively. This has motivated research on developing reliable numerical methods, which amalgamate beneficial properties of symplectic schemes, their thermodynamically consistent generalization (including contact geometry), and spacetime aspects. The present work reports on new results obtained by such a numerical scheme, on wave propagation according to the PTZ model, in one space dimension. The simulation outcomes coincide nicely with the theoretically obtained phase velocity prediction.
\end{abstract}

Keywords

rocks, Poynting-Thomson-Zener rheological model, wave propagation, phase velocity, group velocity

\section{Introduction}

"Rocks flow" - they show deviation from prompt elastic behavior, exhibiting creep and relaxation; in general: delayed and damped response. Probably due to the many levels of various mesoscopic length scales in the structure of a rock [1] (see also [2] on principles and [3, 4] for related effects), the dampings and delays can be observed at various time scales: seconds, hours, days, years each. Knowing these time scales is important and beneficial: by performing a civil engineering technological step faster than the time scale of a disadvantageous effect, we can prevent the full development of that effect in a simpler and cheaper way. In other cases, waiting can be more beneficial: then we have to address a smaller remaining problem, rather than to put much effort in immediately treating the whole change to come.

A concrete example where one can benefit from monitoring/sampling the time dependence of the state of rocks, more closely, of their viscoelastic or rheological behavior, is the Anelastic Strain Recovery (ASR) method [5-7] where in situ stress is determined from how - and from what initial state - borehole rock samples relax during, say, ten days after brought to stress-free boundary condition. The rheological model proved necessary for interpreting the obtainable time series data is a Kluitenberg-Verhás model (in both the deviatoric part and the spherical one).

The Kluitenberg-Verhás model is best understood as the logical generalization of the Kelvin-Voigt and PoyntingThomson-Zener (PTZ) models. Namely, the phenomenon of creep - exponentially declining increase of strain for constant stress -, experimentally observed for various solid materials, can be explained by an extension of Hooke's law with an additional term proportional to the time derivative of strain (a term describing viscosity in solids): this is the Kelvin-Voigt model. Next, some materials exhibit not only creep but also the analogous phenomenon of relaxation - exponentially declining decrease 
of stress for constant strain -, modelling which can be done by having another additional term, the time derivative of stress, in the material law: this is the PTZ model. Finally, the thermodynamical interpretation of the PTZ model given in [8-11] necessitates the assumption of an additional thermodynamical state quantity - a so-called internal variable -, and the outcome is actually an even more general model, the Kluitenberg-Verhás one, which enables one further additional term, proportional to the second time derivative of strain.

While the complete Kluitenberg-Verhás model finds application e.g. in the above-mentioned ASR method, in many practical cases, the PTZ framework - on which we focus in the present work - proves to be satisfactory. This model (with stress, strain, and their first time derivatives) already makes the prediction that measurements of the elasticity coefficients $\left(E^{d e v}=2 G, E^{s p h}=3 K\right)$ that assume a Hooke model behind obtain results that depend on how fast the measured process occured. A consequence of the second law of thermodynamics is that dynamic values must be larger than static ones. This prediction has been confirmed recently for many various types of rock [12-14].

For the Hooke model with the force equilibrium assumption (i.e., neglecting the material time derivative of velocity in the Cauchy momentum equation), analytical calculations are also available for simple yet relevant - symmetric enough - geometries and boundary conditions. One possibility to extend such calculations to rheological models is Volterra's principle. In practice, however, this proves to be a principal possibility only, both because stress boundary condition, the one relevant for most rock mechanical problems, is difficult to realize in Volterra's approach and because calculating the involved operator inverses is mathematically involved. An alternative solution is a recent approach that is also inspired by Volterra's principle but is well-suited to stress boundary problems and requires only solution of a set of linear ordinary differential equations [15-19].

Notably, the force equilibrium assumption neglects transients and wave propagation. Time dependence is present in the processes, as a result of time dependent boundary conditions (modelling, e.g., gradual opening of a tunnel). Nevertheless, for a class of applications, like evaluation of acoustic, resonance-based, and seismic measurements, the description of transients and waves would also be necessary.

Dropping the force equilibrial approximation (i.e., keeping the material time derivative of velocity in the Cauchy momentum equation) makes analytical calculations considerably more difficult. Although analytical results are available (see, e.g., [20]) for some simplest geometric settings and mostly for a real constant viscoelastic Poisson's ratio (an assumption that is not valid for the PTZ model), to go beyond, one may be forced to apply a numerical solution. What can commercial finite element softwares offer for such problems? Well, the situation is discouraging. Even for Hookean wave propagation [21] - and also for wavelike beyond-Fourier models for heat conduction $[22,23]-$, the solution requires large memory demand, large computational time, and the outcome is infected with numerical artefacts: instability, dissipation error (artificial decrease of amplitudes and energies), and dispersion error (artificial oscillations near fast changes) [more details are given in Section 3.2 below]. All these hold for already the simplest settings of a homogeneous one-dimensional sample.

This has led our research group to develop, similarly to recent research activity worldwide [24-33], some own numerical methods, which outperform the commercially existing ones, in each of these aspects. We intend to benefit from the following principles:

- the powerful symplectic methods for reversible systems,

- the second law of thermodynamics, which acts not only as a consistency requirement but, being realized as the mathematical asymptotic stability property of thermodynamical models, can help in stability of the numerical scheme as well [29-30], and

- spacetime aspects encoded in the basic equations of the model: e.g., the balances of mass, of momentum, and of energy are actually a spacetime divergence of a spacetime tensor.

Such a finite difference scheme has been successfully built, its resistance against numerical artefacts has been ensured through accuracy and stability analysis, and test runs have proved that the scheme is precise and fast with low memory demand [21], both for Hooke and PTZ models.

Here presented is a next logical step: investigation of the velocity of waves in the PTZ model via this novel scheme, now that one has such a possibility of simulating wave propagation reliably. Travel of a single stress excitation "bump" along a one-dimensional sample is followed numerically, and the velocity of the tip is numerically determined. For comparison, the analytical derivation of the dispersion relation is utilized to determine the phase velocity and the group velocity as functions of frequency. High-frequency velocities are larger than 
the lower-frequency ones (in tune with that the dynamic Young's modulus is larger than the static one). The numerically found velocity values are in nice agreement with the theoretical phase velocity prediction.

\section{The Kluitenberg-Verhás rheological model family}

A brief introduction of the Kluitenberg-Verhás rheological model family is presented first, to serve as a principal background [8-11], and to show how thermodynamics reveals that experimentally found dynamic coefficients cannot be smaller than their static counterpart. We start with a homogeneous and isotropic Hooke material in the small-strain approximation, excluding plastic changes, damage, and other similar complications, and assume no remarkable temperature changes (consequently, heat conduction and thermal expansion are also neglected here). Stress $\sigma$ is only an elasticity originated $\bar{\sigma}$, the stress-strain relationship being

$$
\bar{\sigma}=E^{d e v} \varepsilon^{d e v}+E^{s p h} \varepsilon^{s p h}
$$

with the spherical and deviatoric components and elastic coefficient constants

$$
\begin{aligned}
& \varepsilon^{s p h}=\frac{1}{3}(\operatorname{tr} \varepsilon) 1, \quad \varepsilon^{d e v}=\varepsilon-\varepsilon^{s p h}, \\
& E^{s p h}=3 K, \quad E^{d e v}=2 G .
\end{aligned}
$$

With constant specific heat capacity $c_{\sigma}$ and mass density $\rho$, specific internal energy is the following function of absolute temperature $T$ and of strain:

$$
e=c_{\sigma} T+\left\{\frac{E^{d e v}}{2 \varrho} \operatorname{tr}\left[\left(\varepsilon^{d e v}\right)^{2}\right]+\frac{E^{s p h}}{2 \varrho} \operatorname{tr}\left[\left(\varepsilon^{s p h}\right)^{2}\right]\right\},
$$

and satisfies the balance of internal energy (heat neglected)

$$
\varrho \dot{e}=\operatorname{tr}(\sigma \dot{\varepsilon})
$$

[overdot denoting time derivative; see also Eq. (9)]. The corresponding specific entropy, satisfying the thermodynamical Gibbs relation $d e=T d \bar{s}+\frac{1}{\varrho} \operatorname{tr}(\bar{\sigma} d \varepsilon)$ and its consequence

$$
\dot{e}=T \dot{\bar{S}}+\frac{1}{\varrho} \operatorname{tr}(\bar{\sigma} \dot{\varepsilon}),
$$

is

$$
\bar{s}=c_{\sigma} \ln \frac{T}{T_{*}}
$$

with an arbitrarily auxiliary constant $T_{*}$, and the balance of entropy is $\varrho \dot{\bar{S}}=\pi_{\bar{s}}$

with zero entropy production $\pi_{\bar{s}}$ (in agreement with that the Hooke system is reversible). In addition, the balance of momentum is

$\varrho \dot{v}=\vec{\nabla} \cdot \sigma$,

with the velocity field $v$, which is kinematically related to the change rate of strain according to

$\dot{\varepsilon}=\frac{1}{2}(\vec{\nabla} \otimes v+v \otimes \overleftarrow{\nabla})$.

We extend this initial model by applying the methodology of internal variables (more specifically, of dynamical degrees of freedom) with an assumed additional symmetric tensorial state quantity $\boldsymbol{\xi}$, corresponding to that rheology manifests itself mainly in the mechanical behavior. It suffices to assume the simplest nonequilibrium thermodynamical extension of entropy,

$s(\varepsilon, e, \xi)=\bar{s}(\varepsilon, e)-\frac{1}{2} t r \xi^{2}$,

where the coefficient $1 / 2$ is fixed using the freedom in rescaling $\xi$, with the possible consequence that, if one has a direct physical interpretation for the additional state variable then an appropriate multiple of that quantity is the $\xi$ here - typically, one does not have a direct intepretation but only some indirect hint. This is actually a virtue of the method of internal variables: even without detailed knowledge about the phenomena in the background, useful and widely applicable models can be derived.

Analogously to Eq. (7), entropy production $\pi_{s}$ can be computed as $\varrho \dot{s}$ and, in virtue of Eq. (10) and the time derivative version of the Gibbs relation Eq. (5), proves to be

$\pi_{s}=\frac{1}{T} \operatorname{tr}(\hat{\sigma} \dot{\varepsilon})-\varrho \operatorname{tr}(\xi \dot{\xi})$,

where $\hat{\sigma}$ denotes the rheology-originated addition in stress with respect to the previous, elastic, stress $\overline{\boldsymbol{\sigma}}$, i.e., $\boldsymbol{\sigma}=\overline{\boldsymbol{\sigma}}+\hat{\boldsymbol{\sigma}}$. The Onsagerian way to ensure the non-negativeness of this entropy production is to consider linear equations

$$
\begin{aligned}
& \hat{\sigma}^{d e v}=l_{11}^{d e v} \dot{\varepsilon}+l_{12}^{d e v}\left(-\varrho T \xi^{d e v}\right), \\
& \hat{\sigma}^{s p h}=l_{11}^{s p h} \dot{\varepsilon}+l_{12}^{s p h}\left(-\varrho T \xi^{s p h}\right), \\
& \dot{\xi}^{d e v}=l_{21}^{d e v} \dot{\varepsilon}+l_{22}^{d e v}\left(-\varrho T \xi^{d e v}\right), \\
& \dot{\xi}^{s p h}=l_{21}^{s p h} \dot{\varepsilon}+l_{22}^{s p h}\left(-\varrho T \xi^{s p h}\right)
\end{aligned}
$$


with positive definite matrices of coefficients

$$
\left(\begin{array}{ll}
l_{11}^{d e v} & l_{12}^{d e v} \\
l_{21}^{d e v} & l_{22}^{d e v}
\end{array}\right), \quad\left(\begin{array}{ll}
l_{11}^{s p h} & l_{12}^{s p h} \\
l_{21}^{s p h} & l_{22}^{s p h}
\end{array}\right) .
$$

With our assumptions above, these coefficients can be regarded as constants. Then the internal variable, for which we do not have direct access, can be eliminated - by appropriately combining equations and their time derivative - , with the result [in which we have switched from $\hat{\sigma}$ to the measurable total $\boldsymbol{\sigma}=\overline{\boldsymbol{\sigma}}+\hat{\boldsymbol{\sigma}}$ and applied Eq. (1)]

$$
\begin{aligned}
& \sigma^{d e v}+\tau^{d e v} \dot{\sigma}^{d e v}=E^{d e v} \varepsilon^{d e v}+\hat{E}^{d e v} \dot{\varepsilon}^{d e v}+\hat{E}^{d e v} \ddot{\varepsilon}^{d e v}, \\
& \sigma^{s p h}+\tau^{s p h} \dot{\sigma}^{s p h}=E^{s p h} \varepsilon^{s p h}+\hat{E}^{s p h} \dot{\varepsilon}^{s p h}+\hat{\hat{E}}^{s p h} \ddot{\varepsilon}^{s p h}
\end{aligned}
$$

which is the Kluitenberg-Verhás model in both the deviatoric and the spherical parts. Positive definiteness of entropy production [hence, of the matrices Eq. (13)] results in the conditions

$$
\begin{aligned}
& \tau^{d e v} \geq 0, \quad E^{d e v} \geq 0, \\
& \hat{E}^{d e v} \geq \tau^{d e v} E^{d e v}, \quad \hat{E}^{d e v} \geq 0, \\
& \tau^{s p h} \geq 0, \quad E^{s p h} \geq 0, \\
& \hat{E}^{s p h} \geq \tau^{s p h} E^{s p h}, \quad \hat{E}^{s p h} \geq 0 .
\end{aligned}
$$

A number of classic rheological models, namely, the Kelvin-Voigt, Maxwell, Jeffrey, and, most importantly for the subsequent considerations, the PTZ model

$$
\begin{aligned}
& \sigma^{d e v}+\tau^{d e v} \dot{\sigma}^{d e v}=E^{d e v} \varepsilon^{d e v}+\hat{E}^{d e v} \dot{\varepsilon}^{d e v}, \\
& \sigma^{s p h}+\tau^{s p h} \dot{\sigma}^{s p h}=E^{s p h} \varepsilon^{s p h}+\hat{E}^{s p h} \dot{\varepsilon}^{s p h},
\end{aligned}
$$

are covered by the Kluitenberg-Verhás model family.

It is important to note that these rheological models are such simple only in the deviatoric-spherical decomposition but not in the traditionally used longitudinal and transversal strains. In practice, fitting of rheological coefficients is possible only after longitudinal and transversal strain data are transformed into the deviatoric and spherical combinations.

\section{The PTZ model in one spatial dimension}

\subsection{The set of equations}

In $1 \mathrm{D}$, the kinematic relationship between velocity and strain Eq. (9) reduces to

$\frac{\partial \varepsilon}{\partial t}=\frac{\partial v}{\partial x}$ the balance of momentum Eq. (8) to

$\rho \frac{\partial v}{\partial t}=\frac{\partial \sigma}{\partial x}$

and the PTZ model Eq. (16) to

$\sigma+\tau \frac{\partial \sigma}{\partial t}=E \varepsilon+\hat{E} \frac{\partial \varepsilon}{\partial t}$

$E$ interpretable as Young's modulus, $\hat{E}$ as the viscosity related coefficient, and $\tau$ as relaxation time. These three equations form the basis of what follows below, together with the inequality [see Eq. (15)]

$\hat{I}=\hat{E}-\tau E>0$

for the 'index of damping' $\hat{I}$ (hereafter, we exclude the degenerate 'doubled Hooke' subcase $\hat{I}=0$ ).

\subsection{Hookean waves - what commercial FEM software can offer}

In [21], the Hooke case ( $\tau=0, \hat{E}=0)$ was realized in the FEM software COMSOL, a promising environment for modelling as the user's own model equations can also be added. The results were disappointing. With large memory demand and large computational time, the outcome was poor, exhibiting numerical artefacts: instability, dissipation error, and dispersion error. With a single stress pulse applied on one end of the sample, which should arrive undistorted periodically at the other end (see Figs. 1-2), some typical findings are displayed in Figs. 3-5.

In addition to the numerical problems, if someone needs many runs with different model coefficients then the time and memory demand also make the available built-in FEM methods impractical.

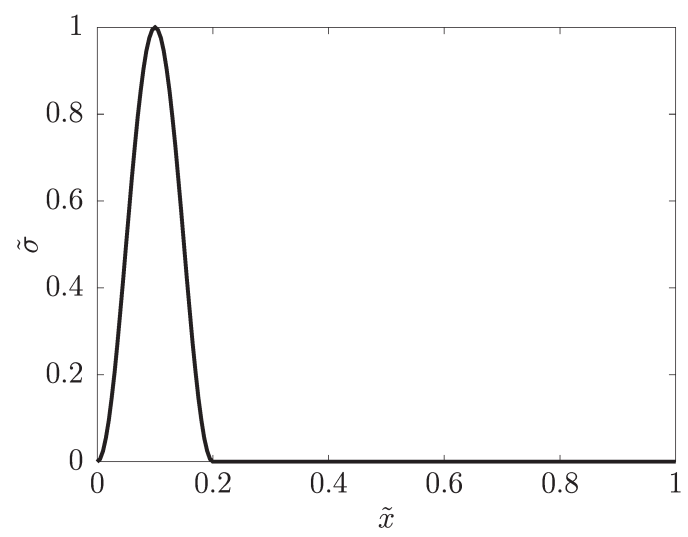

Fig. 1 A single stress pulse: a snapshot of the distribution of stress along the sample at the moment the pulse is fully born at the left end of the sample 


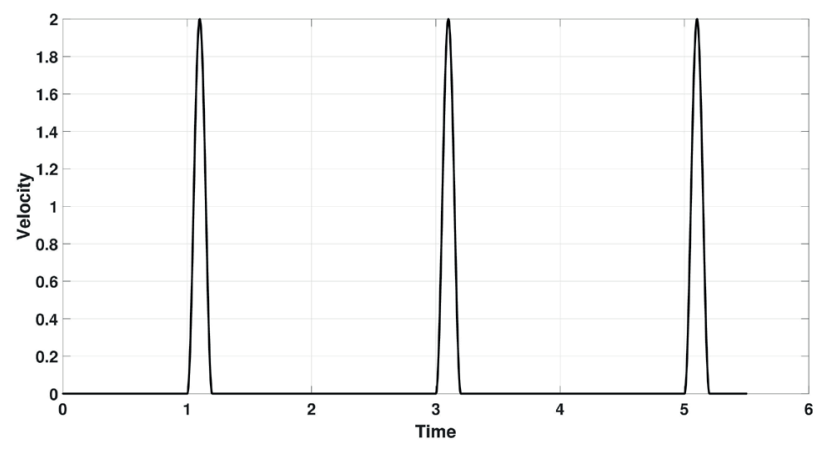

Fig. 2 The expected time dependence of stress at the right endpoint: The stress pulse should arrive at the right endpoint periodically as the function of time in an undistorted shape since wave propagation velocity is a frequency independent constant in the Hooke model

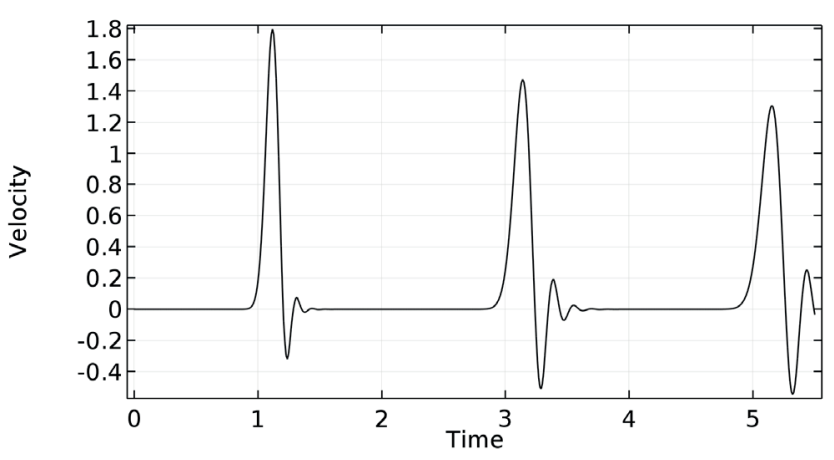

Fig. 3 COMSOL outcome produced with the Backward Differentiation Formula order 2 setting. Both dissipation error (artificial decrease of the amplitude) and dispersion error (artificial oscillations emerging) are observable

\subsection{The principles behind our finite difference scheme}

This failure has motivated us to invent a novel finite difference scheme, which is a second-order accurate extension of a symplectic Euler method reinterpreted as discretized quantity values are bookept according to a pattern that is staggered with half space and time step shifts both [21], see Fig. 6.

In formulae, discrete space and time values are chosen as

$x_{n}=n \Delta x, \quad n=0,1, \ldots, N$,

$t^{j}=j \Delta t, \quad j=0,1, \ldots, J$,

and discrete values of stress and strain are prescribed to these spatial and temporal coordinates:

$\sigma_{n}^{j}$ and $\varepsilon_{n}^{j}$ at $t^{j}, x_{n}$,

while velocity values are placed half-shifted with respect to stress and strain values both in space and time:

$v_{n+1 / 2}^{j-1 / 2}$ at $t^{j}-\frac{\Delta t}{2}, x_{n}+\frac{\Delta x}{2}$.

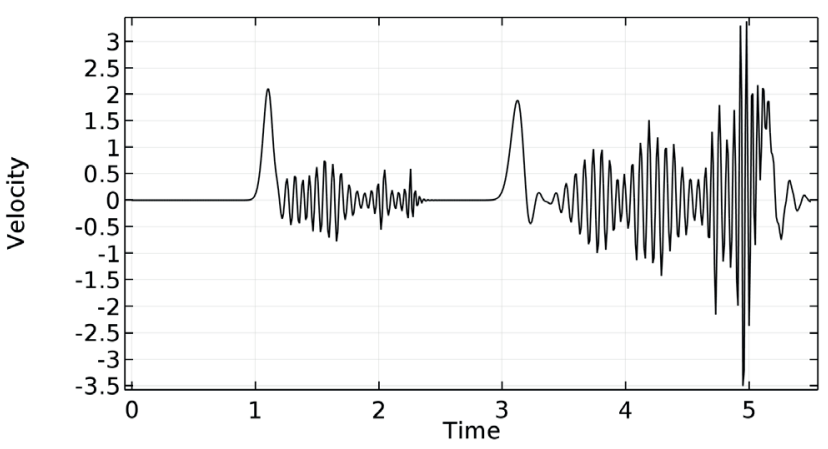

Fig. 4 COMSOL outcome produced with the Backward Differentiation Formula order 5 setting. Dispersion error is particularly dominant

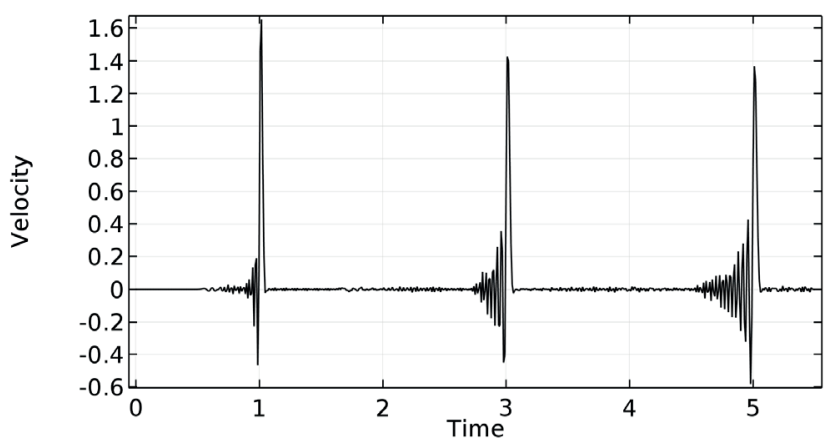

Fig. 5 COMSOL outcome produced with the Dormand-Prince method. Both dissipation error and dispersion error are visible. A fourth setting, the Runge-Kutta base scheme RK34 performs the best, there these artefacts are smaller (but definitely present, nevertheless) space index $n \rightarrow$

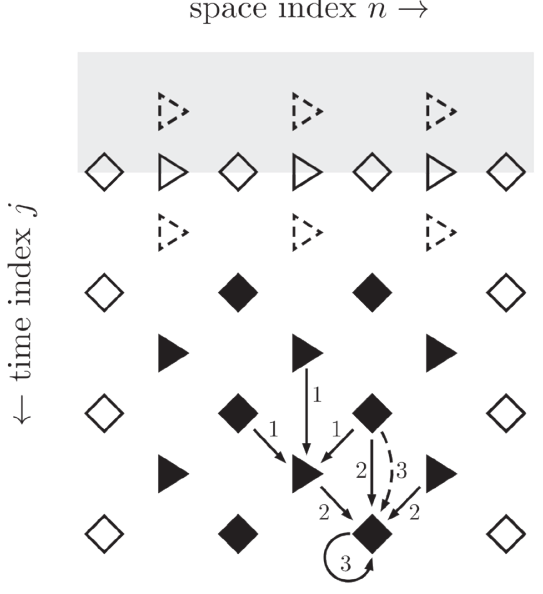

Fig. 6 Visualization of the finite difference numerical scheme. Velocity values stay at triangles, strain and stress values at rhombuses, filled symbols denote values calculated via the scheme, while empty ones represent initial and boundary conditions. First (arrows 1), new velocities are determined from Eq. (24), then (arrows 2) new strains according to Eq. (25), and finally (arrows 3) new stress values are obtained from Eq. (27) (dashed arrow: not present in the Hooke case). Grey indicates initial condition values, which are typically known for a whole time interval in practice. In case the 'grey dashed triangles' are not available then an explicit Euler step can be used to produce the 'white dashed triangles' from the half-grey-half-white triangles and rhombuses (the initial-time values) for starting the scheme 
With these conventions, the continuum equations are discretized as

$$
\begin{aligned}
& \rho \frac{v_{n+1 / 2}^{j+1 / 2}-v_{n+1 / 2}^{j-1 / 2}}{\Delta t}=\frac{\sigma_{n+1}^{j}-\sigma_{n}^{j}}{\Delta x}, \\
& \frac{\varepsilon_{n}^{j+1}-\varepsilon_{n}^{j}}{\Delta t}=\frac{v_{n+1 / 2}^{j+1 / 2}-v_{n-1 / 2}^{j+1 / 2}}{\Delta x}, \\
& \alpha \sigma_{n}^{j}+(1-\alpha) \sigma_{n}^{j+1}+\tau \frac{\sigma_{n}^{j+1}-\sigma_{n}^{j}}{\Delta t} \\
& =E\left[\alpha \varepsilon_{n}^{j}+(1-\alpha) \varepsilon_{n}^{j+1}\right]+\hat{E} \frac{\varepsilon_{n}^{j+1}-\varepsilon_{n}^{j}}{\Delta t}
\end{aligned}
$$

with $\alpha=1 / 2$ to provide second order accuracy of the scheme. Here, the last equation looks implicit but can actually be rewritten in explicit form:

$$
\begin{aligned}
& \sigma_{n}^{j+1}=\frac{1}{1-\alpha+\frac{\tau}{\Delta t}} \\
& \times\left\{\left(\frac{\tau}{\Delta t}-\alpha\right) \sigma_{n}^{j}+E\left[\alpha \varepsilon_{n}^{j}+(1-\alpha) \varepsilon_{n}^{j+1}\right]+\hat{E} \frac{\varepsilon_{n}^{j+1}-\varepsilon_{n}^{j}}{\Delta t}\right\} .
\end{aligned}
$$

\subsection{Our outcomes}

As reported in [21], the same pulse as the one applied in the FEM realizations (Fig. 1) remains undistorted with our scheme even after many bouncings back from the endpoints of the 1D sample in the Hooke case (Figs. 7-8). For a PTZ simulation, the results are shown in Figs. 9-10.

\section{Dispersion relation and velocity}

\subsection{Slow and fast limit}

Analyzing the set of Eqs. (17)-(19) reveals that the PTZ model admits two distinguished time scales, $\tau$ and $\hat{\tau}=\frac{\hat{E}}{E}>\tau$,

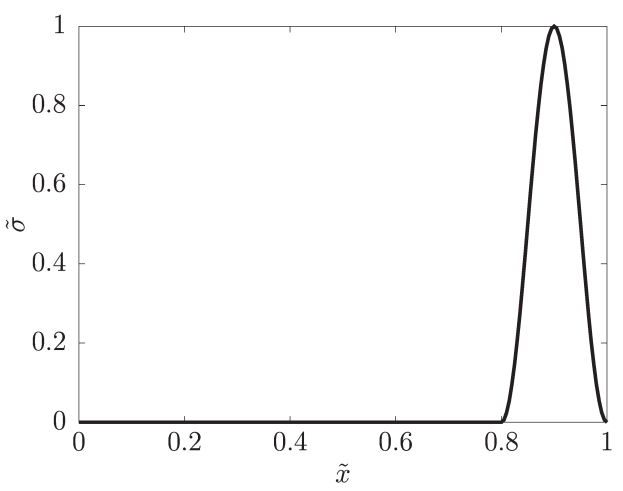

Fig. 7 Snapshot of the stress pulse right before its 15 th bouncing back from the boundary, in the Hookean case

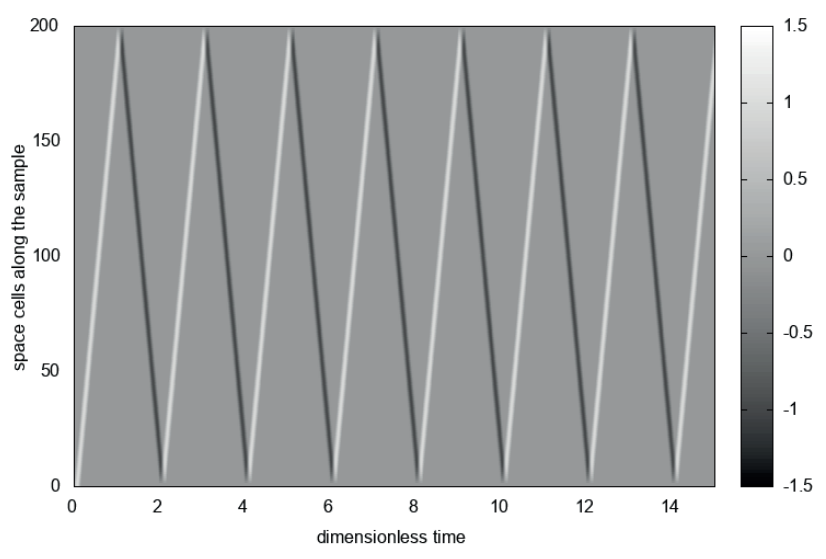

Fig. 8 Spacetime picture of Hookean wave propagation. The calculation is fast, memory demand is low, and there is no need for a fine mesh - already 25 space cells produce a stable and correctly interpretable outcome

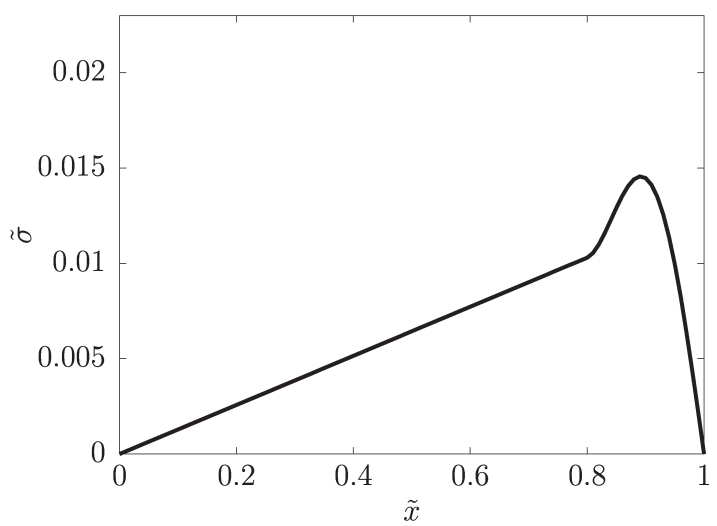

Fig. 9 The shape of the pulse right before its 7th bouncing, for the PTZ model with ratio of 'fast' and 'slow' wave speeds (see more on the notations later). The originally unit-sized pulse has decreased due to rheological dissipation. A widening slower tail can also be observed see its explanation below

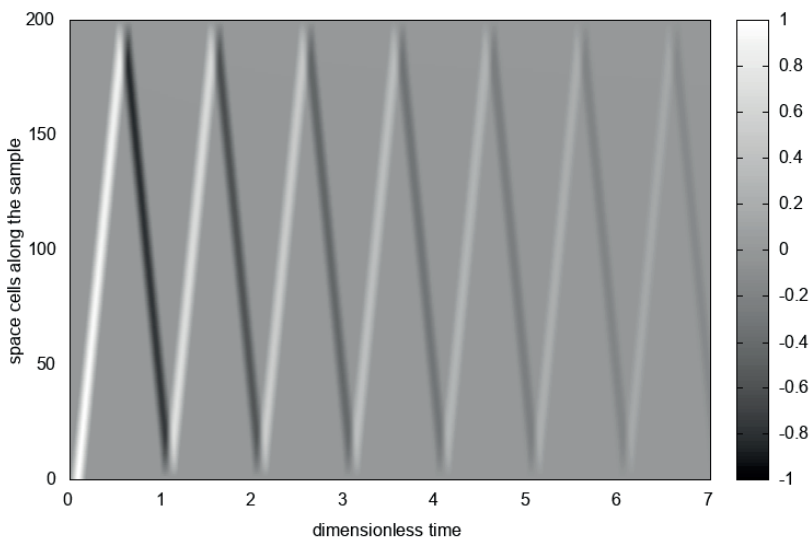

Fig. 10 Spacetime picture in the PTZ case. The tip of the pulse propagates with remarkably constant speed despite the dissipating pulse height and the widening tail. The calculation is similarly fast and memory efficient as in the Hooke case 
the inequality following from Eq. (20). For phenomena much slower than these time scales, the rule-of-thumb approximation of keeping only the lowest time derivative for any quantity present in Eq. (19) gives the Hooke model $\sigma=E \varepsilon$,

formally the $\tau \rightarrow 0, \hat{E} \rightarrow 0(\hat{\tau} \rightarrow 0)$ limit of Eq. (19). The system of Eqs. (17)-(18), Eq. (29) leads to a wave equation for $\nu, \sigma, \varepsilon$ each, with wave speed

$c=\sqrt{\frac{E}{\rho}}$.

On the other side, for processes much faster than the two time scales, keeping the highest time derivatives leads to

$\tau \frac{\partial \sigma}{\partial t}=\hat{E} \frac{\partial \varepsilon}{\partial t}, \frac{\partial \sigma}{\partial t}=\frac{\hat{E}}{\tau} \frac{\partial \varepsilon}{\partial t}$

$\Rightarrow \int_{t_{1}}^{t_{2}}(\cdots) d t$ gives $\Delta_{t_{1} \rightarrow t_{2}} \sigma=\frac{\hat{E}}{\tau} \Delta_{t_{1} \rightarrow t_{2}} \varepsilon$,

that is, for stress and strain changes (e.g., for deviations from initial values), the system effectively behaves like a Hooke one, with dynamic Young's modulus

$E_{\infty}=\frac{\hat{E}}{\tau}, \quad E_{\infty}>E$

The corresponding effective wave equation possesses the wave speed

$\hat{c}=\sqrt{\frac{E_{\infty}}{\rho}}=\sqrt{\frac{\hat{E}}{\tau \rho}}, \hat{c}>c$.

\subsection{Dispersion relation}

For a more rigorous and closer investigation of these aspects, the dispersion relation can be derived:

$\frac{\partial \varepsilon}{\partial t}=\frac{\partial v}{\partial x} \Rightarrow \frac{\partial}{\partial x} \frac{\partial \varepsilon}{\partial t}=\frac{\partial^{2} v}{\partial x^{2}}, \frac{\partial^{2} \varepsilon}{\partial t \partial x}=\frac{\partial^{2} v}{\partial x^{2}}$,

$\rho \frac{\partial v}{\partial t}=\frac{\partial \sigma}{\partial x} \Rightarrow \rho \frac{\partial}{\partial t} \frac{\partial v}{\partial t}=\frac{\partial}{\partial t} \frac{\partial \sigma}{\partial x}, \rho \frac{\partial^{2} v}{\partial t^{2}}=\frac{\partial^{2} \sigma}{\partial t \partial x}$

$\sigma+\tau \frac{\partial \sigma}{\partial t}=E \varepsilon+\hat{E} \frac{\partial \varepsilon}{\partial t}$

$\Rightarrow \frac{\partial}{\partial t} \frac{\partial}{\partial x}\left(\sigma+\tau \frac{\partial \sigma}{\partial t}\right)=\frac{\partial}{\partial t} \frac{\partial}{\partial x}\left(E \varepsilon+\hat{E} \frac{\partial \varepsilon}{\partial t}\right)$,

$\frac{\partial^{2} \sigma}{\partial t \partial x}+\tau \frac{\partial^{3} \sigma}{\partial t^{2} \partial x}=E \frac{\partial^{2} \varepsilon}{\partial t \partial x}+\hat{E} \frac{\partial^{3} \varepsilon}{\partial t^{2} \partial x}$, $\rho \frac{\partial^{2} v}{\partial t^{2}}+\tau \rho \frac{\partial^{3} v}{\partial t^{3}}=E \frac{\partial^{2} v}{\partial x^{2}}+\hat{E} \frac{\partial^{3} v}{\partial t \partial x^{2}}$,

$\frac{\partial^{2} v}{\partial t^{2}}+\tau \frac{\partial^{3} v}{\partial t^{3}}=\frac{E}{\rho}\left(\frac{\partial^{2} v}{\partial x^{2}}+\hat{\tau} \frac{\partial^{3} v}{\partial t \partial x^{2}}\right)$.

Analogously can one obtain

$\frac{\partial^{2} \varepsilon}{\partial t^{2}}+\tau \frac{\partial^{3} \varepsilon}{\partial t^{3}}=\frac{E}{\rho}\left(\frac{\partial^{2} \varepsilon}{\partial x^{2}}+\hat{\tau} \frac{\partial^{3} \varepsilon}{\partial t \partial x^{2}}\right)$,
$\frac{\partial^{2} \sigma}{\partial t^{2}}+\tau \frac{\partial^{3} \sigma}{\partial t^{3}}=\frac{E}{\rho}\left(\frac{\partial^{2} \sigma}{\partial x^{2}}+\hat{\tau} \frac{\partial^{3} \sigma}{\partial t \partial x^{2}}\right)$.

The functions $e^{i k x}$ with all $-\infty<k<\infty$ form a complete set, i.e., any dependent function can be expressed as a linear combination of them. (Or, in a finite space region, the boundary conditions restrict $k$ to a discrete infinite sequence.) When a solution of a rheological wave equation is expanded, the expansion coefficients are time dependent: the solution can be written as $e^{-i \omega t} e^{i k x}$, where $\omega$ may be complex (while $k$ must be real to ensure a complete and orthogonal set of functions), and by substituting the form $e^{-i \omega t} e^{i k x}$ into the rheological wave equation, the relationship between $\omega$ and $k$ turns out to be

$\frac{1-\mathrm{i} \tau \omega}{1-\mathrm{i} \hat{\tau} \omega} \omega^{2}=\frac{E}{\rho} k^{2}$.

\subsection{Phase velocity}

Phase velocity is with which the pattern

$e^{-i \omega t} e^{i k x}=e^{(\operatorname{Im} \omega) t} e^{-i(\operatorname{Re} \omega) t} e^{i k x}=e^{(\operatorname{Im} \omega) t} e^{i k\left(x-v_{\text {phase }} t\right)}$

travels in space as function of time:

$v_{\text {phase }}=\frac{\operatorname{Re} \omega}{k}$

while, in parallel, it decreases exponentially in time (the thermodynamical condition $\tau<\hat{\tau}$ ensures $\omega<0$ so it is really a decrease).

In the limit $|\omega| \rightarrow 0$ (limit of slow processes), we find

$\omega^{2}=c^{2} k^{2}, \omega= \pm c k, \quad \frac{\operatorname{Re} \omega}{k}=\frac{\omega}{k}= \pm c$,

while in the opposite limit $|\omega| \rightarrow \infty$ (limit of fast processes), the result is

$$
\begin{aligned}
& \omega^{2} \frac{-\mathrm{i} \tau \omega}{-\mathrm{i} \hat{\tau} \omega}=\omega^{2} \frac{\tau}{\hat{\tau}}=c^{2} k^{2}, \\
& \omega= \pm \hat{c} k, \frac{\operatorname{Re} \omega}{k}=\frac{\omega}{k}= \pm \hat{c} .
\end{aligned}
$$

Both results confirm the findings above (Eq. (30) and Eq. (33), respectively). 
This is a point where we can see the importance of the PTZ model. Namely, when measuring Young's modulus (or, in 3D, the two elasticity coefficients) of a solid, the speed of uniaxial loading, or the frequency of sound in a wave-based measurement, may influence the outcome and a sufficient interpretation may come in terms of a PTZ model. Indeed, in rock mechanics, dynamic elastic moduli are known to be larger than their static counterparts [13-15], in accord with the thermodynamics-originated inequality in Eq. (32b) (or its 3D version).

\subsection{Group velocity}

For modelling realistic signals, a mixture of modes $e^{-i \omega t} e^{i k x}$ with various $k$ (and, correspondingly, various $\omega$ ) is needed. If the signal contains a continuous collection of values $k$ with a Gaussian distribution around a $k_{0}$ then the signal is of Gaussian form in space (in $x$ ), the peak of which travels with the so-called group velocity, which can be calculated as

$$
v_{\text {group }}=\frac{d(\operatorname{Re} \omega)}{d k}\left(k_{0}\right)
$$

The detailed argument for this formula can be found, e.g., in [34].

It is the existence of more than one mode in a signal that makes the gradually widening tail of the pulse also understandable. Namely, the front moves with $\hat{c}$, the highest phase speed available, while slower modes gradually stay behind, propagating with smaller speeds nearer to $c$.

\subsection{Simulation and its results}

As we could observe in Fig. 10, the tip of the pulse moves with apparently constant velocity between any two bouncings. This enables us to - numerically - measure this velocity. Here the result of this is reported, where the pulse width $\tau_{b}$ has been varied in a wide range. The numerically measured tip velocity is plotted in Fig. 11, as the function of the corresponding real frequency part $\operatorname{Re} \omega=\frac{2 \pi}{\tau_{b}}$.

\section{Conclusions}

The obtained numerical pulse velocity seems to reproduce the theoretically derived phase velocity curve nicely. This is good news. On the other side, being aware of that no finite-time signal can contain a single frequency mode, it is surprising that the frequency distribution (the mode content) in the signal has such a little effect in deviating the pulse velocity from the phase velocity value.

As an example, a Gaussian distribution of modes would lead to a wave packet that propagates with the group

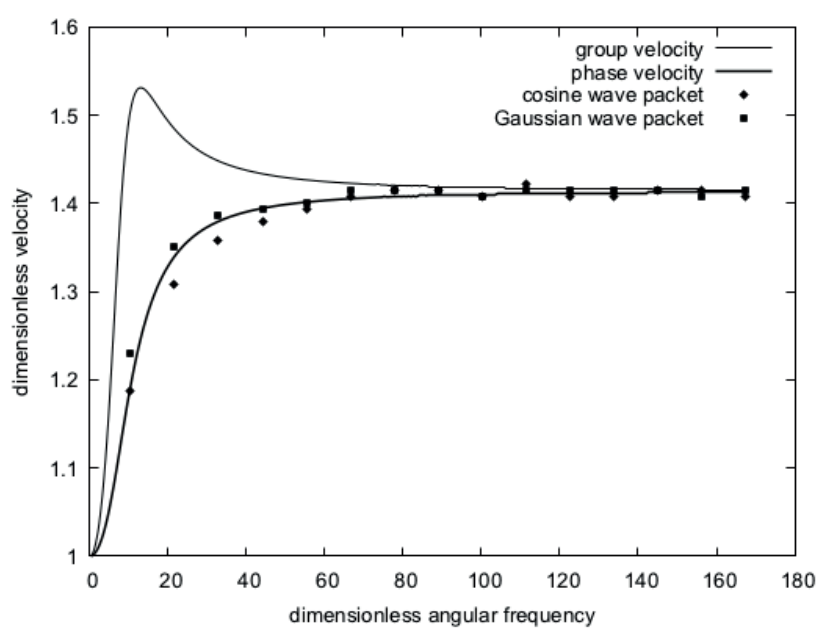

Fig. 11 Numerically measured velocity as the function of the real part of frequency for the PTZ model. Two pulse shapes have been taken, one being a half period of a cosine function and the other being a Gaussian packet (with its infinite tails truncated at an appropriately large distance from the center of the packet). For both pulse shapes, a good agreement with the phase velocity curve can be observed. For comparison, the group velocity curve is also plotted

velocity. Interestingly, even the nearly-Gaussian-in-position packet - with a nearly Gaussian-in-frequency mode content - is found to follow the phase velocity curve better than the group velocity curve. This aspect may need further investigation.

Actually, in addition to the notions of phase velocity, group velocity, and pulse wave velocity, signal velocity and front velocity are also introduced in the literature. Further work is needed to identify how one or some of these can be realized numerically - either as the tip velocity defined here or in some other way.

In parallel, be the numerical scheme as powerful as found in [21], there may be limitations coming from the very fact that it is an explicit finite difference scheme. For comparison, a - similarly intelligent - implicit scheme could also be applied for this same investigation.

Another possibility is an analytical or partially analytical calculation for the continuum system itself, possibly used for a spectral numerical approximation (a one that is principally very different from the spacetime numerical approximation utilized here).

When a satisfactory level of understanding is reached then extension to spatially $2 \mathrm{D}$ and $3 \mathrm{D}$ is reasonable, possibly with a versatility of FEM in order to cope with arbitrary geometries, and then the present line of investigation can be applied for the various wave-based measurement methods used in rock mechanics (see, e.g., [35]). 


\section{Acknowledgement}

The author is grateful to Csaba Asszonyi, József Verhás, Péter Ván, Balázs Vásárhelyi, László Kovács, Róbert Kovács, Mátyás Szücs, and Mohammad Fawaier for providing such a stimulating intellectual environment. This work was supported by the R\&D project NO. 2018-1.1.2-KFI-2018-00207.

\section{Nomenclature}

$t, \Delta t$

$x, \Delta x$

$j=0,1, \ldots, J$

$n=0,1, \ldots, N$

$\alpha$

$E^{d e v}=2 G$

$E^{s p h}=3 K$

E

$E_{\infty}$

$\sigma$

$\varepsilon$

$\rho$

$v$

$T, T_{*}$ time variable, discrete time step

space variable, discrete space step

index for the time variable

index for the space variable

parameter for the numerical scheme

deviatoric elasticity coefficient

spherical elasticity coefficient

Young's modulus (static/slow limit)

Young's modulus (dynamic/fast limit)

stress

strain

mass density

velocity

temperature, auxiliary temperature value

$\cdot$

\section{References}

[1] Kertész, P., Vásárhelyi, B. "A kontinuitás, a homogenitás és az anyagmodell" (Continuity, homogeneity, and the material law), In: Asszonyi, Cs. (ed.) Izotróp kontinuumok anyagtörvénye, MérnökgeológiaKözetmechanika Kiskönyvtár 3, Múegyetemi Kiadó, Budapest, Hungary, 2006, pp. 11-24. (in Hungarian)

[2] Lámer, G. "On the Disordered, Collective and Patterned Movements of Media. Qualitative Analysis of Movements", Periodica Polytechnica Civil Engineering, 63(3), pp. 726-741, 2019. https://doi.org/10.3311/PPci.13685

[3] Permanoon, A., Akhaveissy, A. H. "Effects of Meso-scale Modeling on Concrete Fracture Parameters Calculation", Periodica Polytechnica Civil Engineering, 63(3), pp. 782-794, 2019. https://doi.org/10.3311/PPci.13874

[4] Jiang, Q., Li, J., Luo, Z., Xu, X., Assefa, E., Deng, H. "Study on the Time-lag Failure of Sandstone With Different Degrees of Unloading Damage", Periodica Polytechnica Civil Engineering, 63(1), pp. 206214, 2019. https://doi.org/10.3311/PPci.13260

[5] Matsuki, K., Takeuchi, K. "Three-dimensional in situ stress determination by anelastic strain recovery of a rock core", International Journal of Rock Mechanics and Mining Sciences \& Geomechanics Abstracts, 30(7), pp. 1019-1022, 1993. https://doi.org/10.1016/0148-9062(93)90064-K

[6] Matsuki, K. "Anelastic strain recovery compliance of rocks and its application to in situ stress measurement", International Journal of Rock Mechanics and Mining Sciences, 45(6), pp. 952-965, 2008. https://doi.org/10.1016/j.ijrmms.2007.10.005 isobaric specific heat capacity mass-specific internal energy mass-specific entropy entropy production (rate) internal variable, a symmetric tensor Onsagerian coefficients viscosity-related coefficient Verhás coefficient relaxation time constant creep time constant pulse width (time interval) wave speed, low-frequency limit wave speed, high-frequency limit index of damping wave number angular frequency deviatoric/spherical part of a tensor tensorial (dyadic) product time derivative elastic irreversible/nonequilibrium dimensionless counterpart

[7] Lin, W., Kuwahara, Y., Satoh, T., Shigematsu, N., Kitagawa, Y., ... Koizumi, N. "A case study of 3D stress orientation determination in Shikoku Island and Kii Peninsula, Japan", In: Rock Engineering in Difficult Ground Conditions - Soft Rocks and Karst, Proceedings of the Regional Symposium of the International Society for Rock Mechanics (ISRM), Cavtat, Croatia, 2009, pp. 277-282.

[8] Asszonyi, Cs., Fülöp, T., Ván, P. "Distinguished rheological models for solids in the framework of a thermodynamical internal variable theory", Continuum Mechanics and Thermodynamics, 27, pp. 971986, 2015

https://doi.org/10.1007/s00161-014-0392-3

[9] Asszonyi, Cs., Csatár, A., Fülöp, T. "Szilárd anyagok rugalmas, hőtágulási, képlékeny és reológiai folyamatainak termomechanikája - elmélet és kísérlet" (Thermomechanics of elastic, thermal expansion, plastic and rheological processes of solids - theory and experiment), In: Fülöp, T. (ed.) Termodinamikai módszertan - kontinuumfizikai alkalmazások, Mérnökgeológia-Kőzetmechanika Kiskönyvtár 19, Egyesület a Tudomány és Technológia Egységéért, Budapest, Hungary, 2015, pp. 35-54. (in Hungarian)

[10] Asszonyi, Cs., Fülöp, T., Ván, P. "Kitüntetett szilárdtest-reológiai modellek egy belső változós termodinamikai elmélet keretében" (Distinguished rheological models for solids in the framework of a thermodynamical internal variable theory), In: Fülöp, T. (ed.) Termodinamikai módszertan - kontinuumfizikai alkalmazások, Mérnökgeológia-Kőzetmechanika Kiskönyvtár 19, Egyesület a Tudomány és Technológia Egységéért, Budapest, Hungary, 2015, pp. 11-34. (in Hungarian) 
[11] Asszonyi, Cs., Csatár, A., Fülöp, T. "Elastic, thermal expansion, plastic and rheological processes - theory and experiment", Periodica Polytechnica Civil Engineering, 60(4), pp. 591-601, 2016. https://doi.org/10.3311/PPci.8628

[12] Barnaföldi, G. G., Bulik, T., Cieslar, M., Dávid, E., Dobróka, M., ... Wéber, Z. "First report of long term measurements of the MGGL laboratory in the Mátra mountain range", Classical and Quantum Gravity, 34, Article number: 114001, 2017. https://doi.org/10.1088/1361-6382/aa69e3

[13] Ván, P., Barnaföldi, G. G., Bulik, T., Biró, T., Czellár, S., ... Somlai, L. "Long term measurements from the Mátra Gravitational and Geophysical Laboratory", The European Physical Journal, 228, pp. 1693-1734, 2019. https://doi.org/10.1140/epjst/e2019-900153-1

[14] Davarpanah, S. M., Ván, P., Vásárhelyi, B. "Investigation of relationship between dynamic and static deformation moduli of rocks", Geomechanics and Geophysics for Geo-Energy and Geo-Resources, 6, Article number: 29, 2020. https://doi.org/10.1007/s40948-020-00155-z

[15] Fülöp, T., Béda, Gy. "Hidrosztatikus környezetben nyitott hengerszimmetrikus alagút körüli reológiai időfüggés" (Rheological time dependence around a cylinder-like tunnel in a hydrostatic environment), In: Asszonyi, Cs. (ed.) Kontinuummechanikai feladatok megoldásáról, Mérnökgeológia-Kőzetmechanika Kiskönyvtár 9, Műegyetemi Kiadó, Budapest, Hungary, 2009, pp. 99-114. (in Hungarian)

[16] Fülöp, T., Béda, Gy. "Rheological dynamics of tunnels - an analytical investigation", In: Rock Engineering in Difficult Ground Conditions - Soft Rocks and Karst, Proceedings of the Regional Symposium of the International Society for Rock Mechanics (ISRM), Cavtat, Croatia, 2009, pp. 441-447.

[17] Asszonyi, Cs., Fülöp, T., Szarka, Z., Szücs, M. "Szilárdtest-reológiai feladatok analitikus egzakt megoldása - alagutak körüli mechanikai folyamatok meghatározása" (Analytical exact solution of problems in the rheology of solids - determining mechanical processes around tunnels), In: Fülöp, T. (ed.) Nemegyensúlyi termodinamika és szilárd közegek, Mérnökgeológia-Kőzetmechanika Kiskönyvtár 22, Egyesület a Tudomány és Technológia Egységéért, Budapest, Hungary, 2018, pp. 11-71. (in Hungarian)

[18] Fülöp, T., Szücs, M. "Szilárdtest-reológiai időfüggés meghatározása a Volterra-elv által inspirálva" (Determination of rheological time dependence for solids inspired by Volterra's principle), In: Fülöp, T. (ed.) Termodinamikai módszertan - kontinuumfizikai alkalmazások, Mérnökgeológia-Kőzetmechanika Kiskönyvtár 19, Egyesület a Tudomány és Technológia Egységéért, Budapest, Hungary, 2015, pp. 67-76. (in Hungarian)

[19] Fülöp, T., Szücs, M. "Analytical solution method for rheological problems of solids", [physics.class-ph], arXiv:1810.06350, Cornell University, Ithaca, NY, USA, 2018. [online] Available at: https:// arxiv.org/abs/1810.06350

[20] Christensen, R. M. "Theory of viscoelasticity, An introduction", 2nd ed., Academic Press, New York, NY, USA, 1982. https://doi.org/10.1016/B978-0-12-174252-2.X5001-7

[21] Fülöp, T., Kovács, R., Szücs, M., Fawaier, M. "Thermodynamical Extension of a Symplectic Numerical Scheme with Half Space and Time Shifts Demonstrated on Rheological Waves in Solids", Entropy, 22(2), Article number: 155, 2020.

https://doi.org/10.3390/e22020155
[22] Rieth, Á., Kovács, R., Fülöp, T. "Implicit numerical schemes for generalized heat conduction equations", International Journal of Heat and Mass Transfer, 126(B), pp. 1177-1182, 2018. https://doi.org/10.1016/j.ijheatmasstransfer.2018.06.067

[23] Józsa, V., Kovács, R. "Solving Problems in Thermal Engineering, A Toolbox for Engineers", Springer, Cham, Switzerland, 2020. https://doi.org/10.1007/978-3-030-33475-8

[24] Hairer, E., Wanner, G., Lubich, C. "Geometric Numerical Integration, Structure-Preserving Algorithms for Ordinary Differential Equations", 2nd ed., Springer-Verlag, Berlin, Germany, 2006. https://doi.org/10.1007/3-540-30666-8

[25] Romero, I. "Algorithms for coupled problems that preserve symmetries and the laws of thermodynamics: Part I: Monolithic integrators and their application to finite strain thermoelasticity", Computer Methods in Applied Mechanics and Engineering, 199(25-28), pp. 1841-1858, 2010. https://doi.org/10.1016/j.cma.2010.02.014

[26] Romero, I. "Algorithms for coupled problems that preserve symmetries and the laws of thermodynamics: Part II: fractional step methods", Computer Methods in Applied Mechanics and Engineering, 199(33-36), pp. 2235-2248, 2010. https://doi.org/10.1016/j.cma.2010.03.016

[27] Portillo, D., García Orden, J. C., Romero, I. "Energy-EntropyMomentum integration schemes for general discrete non-smooth dissipative problems in thermomechanics", International Journal for Numerical Methods in Engineering, 112(7), pp. 776-802, 2017. https://doi.org/10.1002/nme.5532

[28] Berezovski, A., Ván, P. "Internal Variables in Thermoelasticity", Springer, Cham, Switzerland, 2017. https://doi.org/10.1007/978-3-319-56934-5

[29] Shang, X., Öttinger, H. C. "Structure-preserving integrators for dissipative systems based on reversible-irreversible splitting", Proceedings of the Royal Society A, 476(2234), Article number: 20190446, 2020 . https://doi.org/10.1098/rspa.2019.0446

[30] Zinner, C. P., Öttinger, H. C. "Numerical Stability with Help from Entropy: Solving a Set of 13 Moment Equations for Shock Tube Problem", Journal of Non-Equilibrium Thermodynamics, 44(1), pp. 43-69, 2019.

https://doi.org/10.1515/jnet-2018-0038

[31] Vermeeren, M., Bravetti, A., Seri, M. "Contact variational integrators", Journal of Physics A: Mathematical and Theoretical, 52, Article number: 445206, 2019. https://doi.org/10.1088/1751-8121/ab4767

[32] Couéraud, B., Gay-Balmaz, F. "Variational discretization of thermodynamical simple systems on Lie groups", Discrete \& Continuous Dynamical Systems - S, 13(4), pp. 1075-1102, 2020. https://doi.org/10.3934/dcdss.2020064

[33] Gay-Balmaz, F., Yoshimura, H. "Variational discretization of the nonequilibrium thermodynamics of simple systems", Nonlinearity, 31(4), pp. 1673-1705, 2018. https://doi.org/10.1088/1361-6544/aaa10e 
[34] Fülöp, T. "Rugalmasságtani és reológiai lineáris feladatok" (Linear problems of elasticity and rheology) In: Asszonyi, Cs. (ed.) Kontinuummechanikai feladatok megoldásáról, MérnökgeológiaKőzetmechanika Kiskönyvtár 9, Müegyetemi Kiadó, Budapest, Hungary, 2009, pp. 11-52. (in Hungarian) (online) Available at: http://montavid.hu/montavid_pdfs/mernokgeologia-kozetmechanika_kiskonyvtar_09.pdf
[35] Malhotra, V. M., Carino, N. J. (eds.) "Handbook on nondestructive testing of concrete", 2nd ed., CRC Press, Boca Raton, FL, USA, 2003.

https://doi.org/10.1201/9781420040050 